\title{
Eukaryotic Initiation Factor 3
}

National Cancer Institute

\section{Source}

National Cancer Institute. Eukaryotic Initiation Factor 3. NCI Thesaurus. Code C132066.

A protein complex comprised of 13 nonidentical subunits (EIF3A-M) that is involved in translation initiation and the disassembly and recycling of post-termination ribosomal complexes. 